\title{
Rancang Bangun Sistem Kalibrasi Alat Ukur Tekanan Rendah
}

\author{
Sugeng Hariyadi ${ }^{1}$, Fitria Hidayanti ${ }^{1}$, Sunartoto Gunadi $^{1}$ \\ ${ }^{1}$ Program Studi Teknik Fisika, Fakultas Teknik dan Sains, Universitas Nasional, Jakarta \\ Korespondensi: hariyadi.sugeng.sh@gmail.com
}

\begin{abstract}
ABSTRAK. Persaingan industri peralatan ukur sekarang sangatlah berat, hal ini mengakibatkan mereka harus selalu mempertahankan atau meningkatkan kualitas produk mereka. Untuk mempertahankan produk, mereka harus menggunakan peralatan-peralatan ukur yang tepat dan ini adalah suatu keharusan. Seperti kita ketahui kalibrasi alat ukur adalah salah satu cara untuk mempertahankan alat ukur tersebut berfungsi dengan baik. Alat ukur tekanan seperti pressure gauge, pressure transmitter, dan alat-alat ukur tekanan lain harus selalu dikalibrasi dan untuk alasan ini kita harus menggunakan standard primer seperti Dead Weight Tester (DWT). Disebabkan karena ketelitian DWT yang sangat tinggi maka pembuatan alat ukur ini sangatlah pelik karena harus ditunjang dengan permesinan yang tinggi kepresisiannya. Pada penelitian ini kami telah membuat sebuah standard primer tekanan dengan cara yang lebih sederhana, namun ketelitian dari instrumen tetap tinggi. Instrumen ini dirancang dan didedikasikan untuk kalibrasi portable. Prinsip dasar dari alat ukur ini adalah manometer pipa-U yang berisi cairan aquabides, dan merealisasikan tekanan dengan persamaan $\mathrm{P}=\rho . \mathrm{g} . \Delta \mathrm{h}$ '. Densitas aquabides secara langsung dihitung dengan menggunakan persamaan fungsi temperatur, sedangkan perbedaan tinggi dua permukaan cairan diukur menggunakan Laser Displacement Sensor (LDS), dan nilai percepatan gravitasi yang digunakan adalah $9.781369 \mathrm{~m} / \mathrm{s} 2$. Pengujian alat ini dilakukan dengan menghitung besarnya ketidakpastiaan instrumen dimana kita mendapatkan $0.18 \%$ dari skala maksimum. Berdasarkan pengujian validasi yang dilakukan oleh Lembaga Nasional Metrologi Indonesia (LIPI) alat ini bisa diterima sebagai standard primer.
\end{abstract}

Kata kunci: Kalibrasi, alat ukur tekanan, Manometer pipa-U, rentang tekanan rendah, densitas akuabides, pengukuran suhu, ketidakpastian.

\section{PENDAHULUAN}

Persaingan di dunia industri yang semakin ketat saat ini menuntut pelaku industri untuk senantiasa meningkatkan kualitas produk yang dihasilkan. Beberapa faktor yang dapat menentukan kualitas produk yang dihasilkan diantaranya adalah; sumber daya manusia (SDM), peralatan produksi dan alat ukur. Alat ukur dapat berfungsi sebagai salah satu penentu kualitas produk karena dari awal kegiatan produksi kebenaran nilai ukur yang terbaca adalah informasi yang sangat penting untuk melajutkan proses berikutnya sampai dengan proses produksi selesai, untuk proses terakhir pun setelah produk jadi sebelum di pasarkan, produk harus diuji dengan menggunakan alat-alat ukur yang dapat dipercaya kebenarannya. Dengan demikian alat-alat ukur yang akurat, teliti dan mampu menunjukan nilai kebenaran setiap pengukuran sangat diperlukan [1-3]. Untuk mengetahui sejauh mana keakuratan dan ketelitian alat ukur maka perlu dilakukan kalibrasi. Kalibrasi adalah kegiatan membandingkan alat ukur terhadap standard ukur, agar diperoleh informasi tentang seberapa jauh penyimpangan alat ukur terhadap standard tersebut [4].

Salah satu alat ukur dari sekian banyak alat ukur yang perlu dikalibrasi adalah alat ukur tekanan. Alat ukur tekanan seperti pressure gauge, pressure transmitter, dan alat-alat ukur tekanan lain pada umumnya oleh laboratorium kalibrasi di Indonesia dikalibrasi dengan menggunakan standard primer Dead Weight Tester (DWT). DWT terdiri dari 3 komponen utama; unit piston, silinder, dan massa tambahan sebagi beban. Karena ukuran yang sangat presisi dari komponenkomponen tersebut maka pembuatan $D W T$ amat sulit dilakukan apabila tidak ditunjang oleh mesin-mesin dan peralatan yang presisi pula [5].

Tujuan dari penelitian ini adalah dapat dibuatnya standard primer yang lebih mudah pembuatannya, dengan menggunakan komponen yang mudah diperoleh, dan keakuratan tetap 
dapat dihandalkan, serta alat dirancang dan dibuat agar dapat dibawa kemana-mana saat melakukan kalibrasi.

\section{LANDASAN TEORI}

Liquid coloum atau manometer pipa-U adalah sebuah standard primer pada pengukuran tekanan, cara kerja dari alat ini adalah bekerja menurut prinsip tekanan hidrostatis dengan persamaan

$$
P=\rho g \Delta h
$$

Dimana: $\mathrm{P}$ adalah tekanan satuan $\mathrm{Pa} ; \rho$ adalah densitas cairan yang bekerja dengan satuan $\mathrm{kg} / \mathrm{m}^{3}$; g adalah konstanta gravitasi lokal dengan satuan $\mathrm{m} / \mathrm{s}^{2}$; dan $\Delta \mathrm{h}$ adalah perubahan ketinggian permukaan pada tabung pipa-U dengan satuan $\mathrm{m}$.

Perhitungan besarnya densitas cairan yang dipengaruhi perubahan suhu sekitar dapat dihitung dengan persamaan [1].

$$
\rho=a_{5}\left[1 \frac{\left(t+a_{1}\right)^{2}\left(t+a_{2}\right)}{a_{3}\left(t+a_{4}\right)}\right]
$$

Besarnya nilai variabel-variabel yang dimasukan ke dalam persamaan tersebut adalah: a1 $1{ }^{\circ} \mathrm{C}=$ $-3.983035 \pm 0.00067 ; \mathrm{a} 2 /{ }^{\circ} \mathrm{C}=301.797 ; \mathrm{a} 3 /{ }^{\circ} \mathrm{C} 2=522528.9 ; \mathrm{a} 4 /{ }^{\circ} \mathrm{C}=69.34881 ; \mathrm{a} 5 /(\mathrm{kg} \mathrm{m}-3)=$ $999.974950 \pm 0.00084$

\section{METODOLOGI PENELITIAN}

Penelitian ini diawali dengan perancangan sistem kalibrasi alat ukur tekanan rendah rentang ukur tekanan 10-500 Pascal. Susunan masing-masing komponen harus dilakukan secara efektif, baik berupa penempatan masing-masing komponen, koneksinya serta pemasangan sensor yang diperlukan. Perancangan dituangkan dalam gambar 1. Secara diagram blok dapat dijelaskan seperti gambar 2 [6-7].

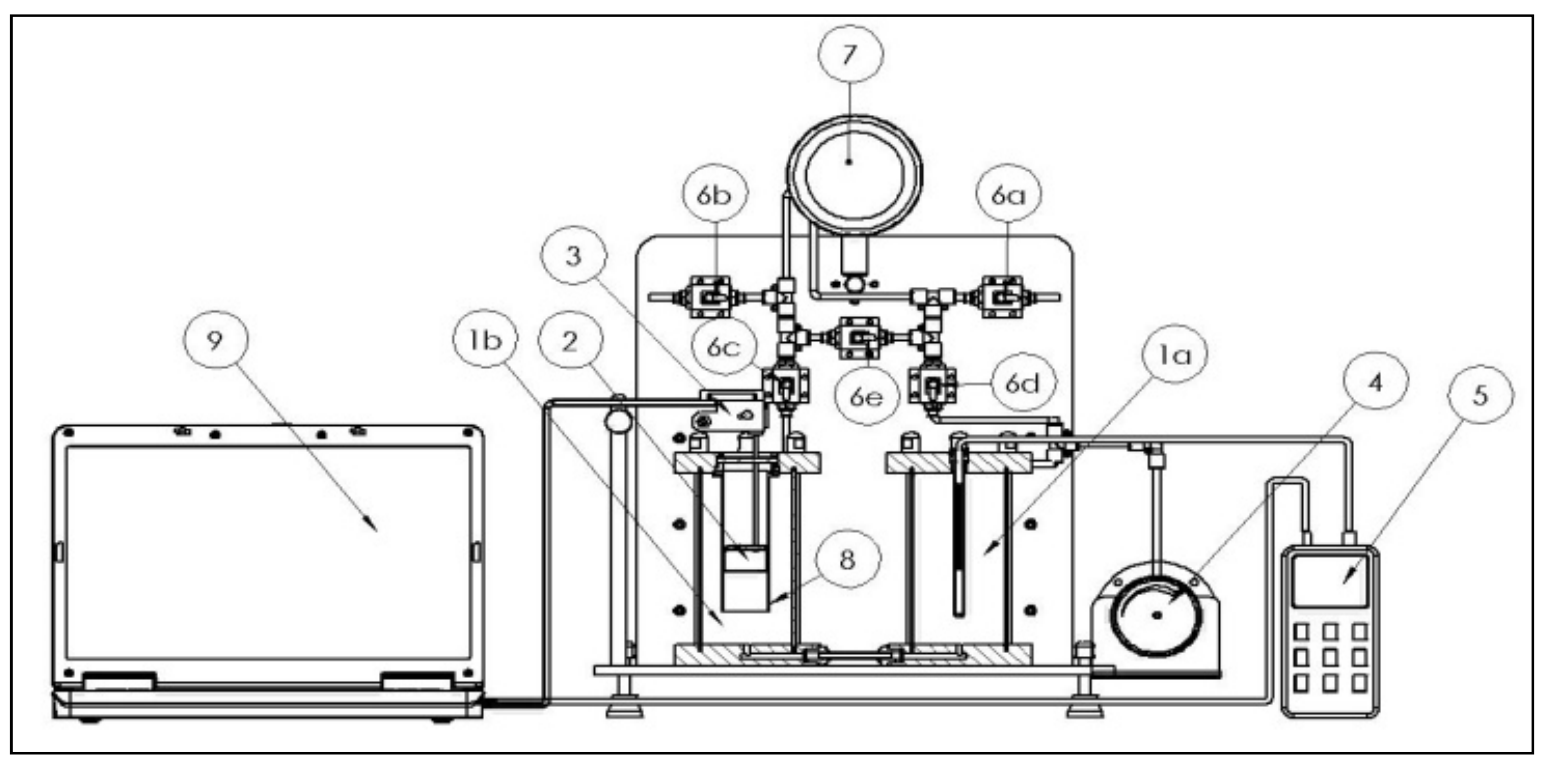

GAMBAR 1. Perancangan Sistem Kalibrasi Alat Ukur Tekanan Rentang 10-500 Pa.

(1a) Tabung 1 Pipa U; (1b) Tabung 2 pipa U; (2) Pelampung dengan sebuah Reflektor; (3) Laser Displacement Sensor; (4) Pompa/sumber tekanan; (5) Sensor Suhu (6a,6b,6c,6d,6e) 
Katup Koneksi; (7) UUT; (8) Selubung Pandu Pelampung; (9) laptop / komputer sebagai pengolah data.

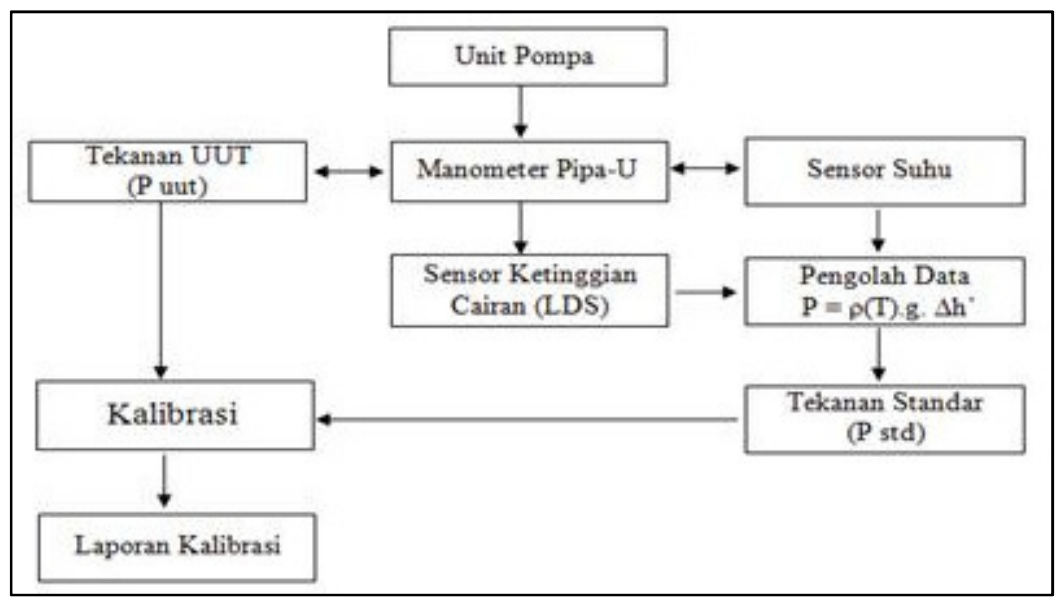

GAMBAR 2. Diagram Blok Alur Kerja Kalibrasi Alat Ukur Tekanan Rendah.

Cara kerja sistem kalibrasi alat ukur tekanan rendah tersebut sebagai berikut : diawali oleh sebuah pompa yang memberikan tekanan ke medium tekanan (udara) masuk ke dalam tabung 1 pipa-U yang berisi cairan akuabides, mengakibatkan terjadinya perbedaan ketinggian antara kedua permukaan cairan dalam tabung 1 dan tabung 2 pipa-U. Besarnya perubahan ketinggian permukaan cairan $\left(\Delta \mathrm{h}^{\prime}\right)$ ini akan diukur dengan sebuah alat Laser Displacement Sensor (LDS) yang memiliki resolusi $0.01 \mathrm{~mm}$ jangkaun $\sim 95 \mathrm{~mm}$ yang diletakkan pada tabung 2 pipa-U yang diarahkan pada sebuah reflektor berbahan aluminium yang sangat ringan ditempatkan mengapung dipermukaan cairan tersebut.

Densitas cairan akuabides dihitung menggunakan sebuah persamaan 2 yaitu persamaan densitas sebagai fungsi suhu. Suhu akuabides ini, diukur menggunakan sensor suhu berupa platinum iridium yang memiliki resolusi $0.01{ }^{\circ} \mathrm{C}$ yang kemudian dicatat dikomputer secara otomatis.

Nilai percepatan gravitasi yang digunakan adalah $9.781369 \mathrm{~m} / \mathrm{s}^{2}$, yang merupakan nilai percepatan gravitasi dimana sistem ini dibangun. Dengan mengetahui parameter-parameter tekanan tersebut maka kita dapat merealisasikan satuan tekanan menurut persamaan $\mathrm{P}=\rho$. g. $\Delta$ h', sehingga dapat digunakan untuk mengkalibrasi alat ukur tekanan rendah dengan rentang 10 pa s/d 500 Pascal [8-9].

\section{HASIL DAN PEMBAHASAN}

Dengan mempersiapkan terlebih dahulu kebutuhan bahan sesuai dengan fungsi masing-masing komponen tahap berikutnya dilakukan proses pembuatan sistem kalibrasi alat ukur tekanan rendah rentang ukur tekanan 10-500 pascal. Hasil pembuatan terlihat pada gambar 3 .

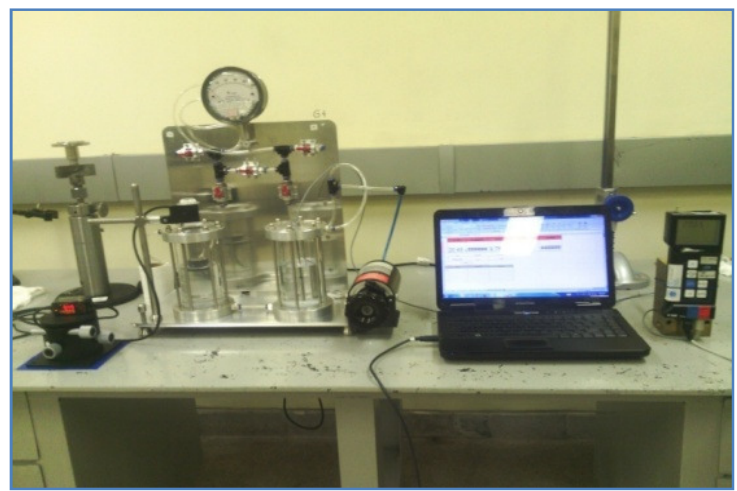

GAMBAR 3. Sistem kalibrasi alat ukur tekanan rendah 10-500 Pascal. 
Setelah alat jadi, kemudian dilakukan pengujian. Pengujian dilakukan dengan analisis perhitungan ketidakpastian dari alat yang dibuat. Dengan analisis perhitungan ketidakpastian akan diketahui sejauh mana keakuratan alat ini untuk bisa digunakan sebagai standard primer alat ukur tekanan rendah. Perhitungan ketidakpastian dilakukan melalui langkah-langkah berikut.

\section{Penentuan model matematis sistem}

Model matematis yang digunakan pada sistem yang dibangun sebagai standard primer tekanan rendah ini ditunjukkan oleh persamaan (3).

$$
\text { Pstd }=\rho . g \cdot 2 \Delta h^{\prime}
$$

Dimana:

Pstd adalah tekanan yang dihasilkan oleh sistem yang dibangun $(\mathrm{Pa})$ $\rho$ adalah densitas cairan (akuabides) $\left(\mathrm{kg} / \mathrm{m}^{3}\right)$

g adalah konstanta gravitasi lokal dimana sistem digunakan $\left(\mathrm{m} / \mathrm{s}^{2}\right)$

$\Delta$ h' adalah perubahan ketinggian permukaan pada tabung 1 pipa-U, diukur oleh LDS (m)

\section{Penentuan komponen-komponen ketidakpastian}

Komponen-komponen ketidakpastian yang berkontribusi pada sistem yang dibangun sebagai standard primer tekanan rendah ditentukan berdasarkan persamaan 3 antara lain:

- Densitas cairan.

Seperti yang telah dijelaskan di metode, densitas cairan tidak diukur secara langsung, melainkan dihitung menggunakan persamaan 2, yaitu persamaan densitas sebagai fungsi suhu cairan. Untuk itu komponen ketidakpastiannya berasal dari sistem pengukuran suhu cairan, antara lain sertifikat sensor suhu, keseragaman suhu cairan, kestabilitas suhu cairan dan sensor suhu.

Koefisien sensitivitas dari densitas terhadap perubahan suhu dan juga koefisien sensitivitas dari tekanan terhadap perubahan densitas, sesuai dengan peramaan (4) dan (5).

$$
\begin{gathered}
c_{T}=\frac{\partial \rho}{\partial T}=-a_{5}\left[\frac{\left(a_{1}+T\right)^{2}}{a_{3}\left(a_{4}+T\right)}-\frac{\left(a_{1}+T\right)^{2}\left(a_{2}+T\right)}{a_{3}\left(a_{4}+T\right)^{2}}+\frac{\left(a_{2}+T\right)\left(2 a_{1}+2 T\right)}{a_{3}\left(a_{4}+T\right)}\right] \\
c_{\rho}=\frac{\partial p}{\partial \rho}=g .2 \Delta h^{\prime}
\end{gathered}
$$

- Konstanta gravitasi lokal.

Konstanta gravitasi lokal yang digunakan disini adalah konstanta gravitasi laboratorium tempat alat ini dibuat, yang diukur menggunakan gravimeter absolute. Sehingga komponen ketidakpastiannya berasal dari sertifikat pengukuran gravitasi secara absolut. Koefisien sensitivitas tekanan terhadap perubahan gravitasi lokal, sesuai dengan persamaan (6).

$$
c_{g}=\frac{\partial p}{\partial g}=2 . \rho \cdot \Delta h^{\prime}
$$

- Pengukuran perubahan ketinggian permukaan cairan

Perubahan ketinggian cairan ( $\Delta$ h') karena diukur dengan menggunakan LDS, maka komponen-komponen ketidakpastiannya, antara lain sertifikat LDS, kestabilan pembacaan LDS, vertikalitas dari berkas sinar LDS. 
Koefisien sensitifitas tekanan terhadap perubahan tinggi permukaan cairan pada tabung 1 pipa-U, sesuai dengan persamaan (7).

$$
c_{\Delta h^{\prime}}=\frac{\partial p}{\partial \Delta h^{\prime}}=2 \cdot \rho \cdot g
$$

\section{Perhitungan Ketidakpastian Sistem yang Dibangun}

Ketidakpastian sistem yang sedang dibangun dihitung berdasarkan kombinasi komponenkomponen ketidakpastian yang berpengaruh dan ditampilkan dengan tabel-tabel berikut:

- Densitas cairan

Tabel 4.2. Ketidakpastian sistem pengukuran suhu untuk perhitungan densitas cairan. Dari table 4.2 dapat dilihat nilai ketidakpastian bentangan yang diperoleh dari sistem pengukuran suhu yaitu $0.077^{\circ} \mathrm{C}$, ini kemudian akan dijadikan sebagai komponen utama pada penentuan ketidakpastian densitas cairan, seperti ditunjukkan pada tabel 1.

TABEL 1. Ketidakpastian sistem pengukuran suhu untuk perhitungan densitas cairan

\begin{tabular}{|c|c|c|c|c|c|c|c|c|c|c|c|c|c|}
\hline \multirow[t]{2}{*}{ No. } & \begin{tabular}{c|} 
Komponen \\
Ketidakpastian
\end{tabular} & Estimasi & \multirow[t]{2}{*}{ Satuan } & \multirow[t]{2}{*}{ Simbol } & $\begin{array}{c}\text { Lebar } \\
\text { Distribusi }\end{array}$ & \multirow[t]{2}{*}{ Distribusi } & \multirow[t]{2}{*}{ Pembagi } & DOF & \begin{tabular}{l|} 
Ketidakpa \\
stian Baku
\end{tabular} & $\begin{array}{c}\text { Koefisien } \\
\text { Sensitifitas }\end{array}$ & \multirow[t]{2}{*}{$c_{i} \cdot u_{i}$} & \multirow[t]{2}{*}{$\left(c_{i} \cdot u_{i}\right)^{2}$} & \multirow[t]{2}{*}{$\left(c_{i} \cdot u_{i}\right)^{4} / v$} \\
\hline & $x$ & $\mathrm{xi}$ & & & $2 a$ & & & vi & ui & $\mathrm{ci}$ & & & \\
\hline 1 & $\begin{array}{c}\text { Sertifikat Sensor } \\
\text { Suhu }\end{array}$ & 20.00 & ${ }^{\circ} \mathrm{C}$ & Tc & 0.05 & Normal & 2 & 60 & 0.025 & 1 & 0.025 & $6.3 \mathrm{E}-04$ & $6.5 \mathrm{E}-09$ \\
\hline 2 & $\begin{array}{l}\text { Homogenitas } \\
\text { Suhu Air }\end{array}$ & 0 & ${ }^{\circ} \mathrm{C}$ & Ts & 0.1 & Segiempat & 1.73 & 50 & 0.0288675 & 1 & 0.028868 & $8.3 \mathrm{E}-04$ & $1.4 \mathrm{E}-08$ \\
\hline \multirow[t]{6}{*}{3} & \begin{tabular}{|c|} 
Pengulangan / \\
Stabilitas Suhu Air
\end{tabular} & 0 & ${ }^{\circ} \mathrm{C}$ & Tt & 0.02 & Segiempat & 1.73 & 50 & 0.0057735 & 1 & 0.005774 & $3.3 \mathrm{E}-05$ & $2.2 \mathrm{E}-11$ \\
\hline & & & & & & & & & & \multicolumn{2}{|l|}{ Jumlah } & $1.5 \mathrm{E}-03$ & $2.0 \mathrm{E}-08$ \\
\hline & & & & & & & & & & \multicolumn{2}{|c|}{$\begin{array}{l}\text { Ketidakpastian Baku } \\
\text { Gabungan }\end{array}$} & \multicolumn{2}{|c|}{0.039} \\
\hline & & & & & & & & & & \multicolumn{2}{|l|}{ Eff. DOF $\left(v_{\text {eff }}\right)$} & \multicolumn{2}{|c|}{108.957} \\
\hline & & & & & & & & & & \multicolumn{2}{|c|}{ Faktor Cakupan } & \multicolumn{2}{|c|}{1.98} \\
\hline & & & & & & & & & & \multicolumn{2}{|c|}{\begin{tabular}{|l|} 
Keidakpastian \\
Bentangan
\end{tabular}} & 0.077 & ${ }^{\circ} \mathrm{C}$ \\
\hline
\end{tabular}

TABEL 2. Ketidakpastian densitas cairan

\begin{tabular}{|c|c|c|c|c|c|c|c|c|c|c|c|c|c|}
\hline \multirow[t]{2}{*}{ No. } & $\begin{array}{l}\text { Komponen } \\
\text { Ketidakpastian }\end{array}$ & Estimasi & \multirow[t]{2}{*}{ Satuan } & \multirow[t]{2}{*}{ Simbol } & $\begin{array}{c}\text { Lebar } \\
\text { Distribusi }\end{array}$ & \multirow[t]{2}{*}{ Distribusi } & \multirow[t]{2}{*}{ Pembagi } & DOF & $\begin{array}{c}\text { Ketidakpasti } \\
\text { an Baku }\end{array}$ & \begin{tabular}{|c|} 
Koefisien \\
Sensitifitas
\end{tabular} & \multirow[t]{2}{*}{$\mathrm{c}_{\mathrm{i}} \cdot \mathrm{u}_{\mathrm{i}}$} & \multirow[t]{2}{*}{$\left(c_{i} \cdot u_{i}\right)^{2}$} & \multirow[t]{2}{*}{$\left(c_{i} \cdot u_{i}\right)^{4} / v$} \\
\hline & $X$ & xi & & & $2 \mathrm{a}$ & & & $\dot{\mathrm{v}}$ & ui & ci & & & \\
\hline \multirow[t]{6}{*}{1} & Suhu & 20.00 & ${ }^{\circ} \mathrm{C}$ & $T$ & 0.077 & Normal & 2 & 60 & 0.03827785 & 1.5419 & 0.059 & $3.5 \mathrm{E}-03$ & $2.0 \mathrm{E}-07$ \\
\hline & & & & & & & & & & \multicolumn{2}{|l|}{ Jumlah } & $3.5 \mathrm{E}-03$ & $2.0 \mathrm{E}-07$ \\
\hline & & & & & & & & & & \multicolumn{2}{|c|}{ Ketidakpastian Baku } & \multicolumn{2}{|c|}{0.059} \\
\hline & & & & & & & & & & \multicolumn{2}{|c|}{ Eff. DOF $\left(v_{\text {eff }}\right)$} & \multicolumn{2}{|c|}{60.000} \\
\hline & & & & & & & & & & \multicolumn{2}{|c|}{ Faktor Cakupan } & \multicolumn{2}{|c|}{2.00} \\
\hline & & & & & & & & & & \multicolumn{2}{|c|}{\begin{tabular}{|l|} 
Keidakpastian \\
Bentangan
\end{tabular}} & 0.12 & $\mathrm{~kg} \cdot \mathrm{m}^{-3}$ \\
\hline
\end{tabular}

Dari Tabel 2 diperoleh ketidakpastian bentangan densitas cairan yang digunakan pada sistem kalibrasi tekanan rendah adalah $0.12 \mathrm{~kg} . \mathrm{m}-3$, atau $0.01 \%$ dari densitas nominal cairan. Nilai ini nantinya akan dimasukkan sebagai komponen utama pada penentuan ketidakpastian sistem yang dibangun, seperti yang ditunjukkan pada tabel 4.6.

- Konstanta gravitasi

Tabel 3 menunjukkan ketidakpastian bentangan konstanta gravitasi lokal yang diperoleh dari setifikat pengukuran sebesar $4.9 \times 10^{-5} \mathrm{~m} \cdot \mathrm{s}^{-2}$. Nilai ini kemudian akan dimasukkan sebagai komponen utama pada penentuan ketidakpastian sistem yang dibangun, seperti ditunjukkan pada tabel 5 . 
TABEL 3. Ketidakpastian konstanta gravitasi local.

\begin{tabular}{|c|c|c|c|c|c|c|c|c|c|c|c|c|c|}
\hline \multirow[t]{2}{*}{ No. } & $\begin{array}{c}\text { Komponen } \\
\text { Ketidakpastian }\end{array}$ & Estimasi & \multirow[t]{2}{*}{ Satuan } & \multirow[t]{2}{*}{ Simbol } & \multirow{2}{*}{\begin{tabular}{|c|}
$\begin{array}{c}\text { Lebar } \\
\text { Distribusi }\end{array}$ \\
$2 a$ \\
\end{tabular}} & \multirow[t]{2}{*}{ Distribusi } & \multirow[t]{2}{*}{ Pembagi } & DOF & \begin{tabular}{|l|} 
Ketidak \\
pastian \\
\end{tabular} & \begin{tabular}{|c|} 
Koefisien \\
Sensitifitas \\
\end{tabular} & \multirow[t]{2}{*}{$\mathrm{c}_{\mathrm{i}} \cdot \mathrm{u}_{\mathrm{i}}$} & \multirow[t]{2}{*}{$\left(c_{i} \cdot u_{i}\right)^{2}$} & \multirow[t]{2}{*}{$\left(c_{i} \cdot u_{i}\right)^{4} / v$} \\
\hline & $\mathrm{X}$ & $x i$ & & & & & & vi & ui & ci & & & \\
\hline \multirow[t]{6}{*}{1} & Sertifikat Gravitasi & 9.781369 & $\mathrm{~m} \cdot \mathrm{s}^{-2}$ & g & 4.89E-05 & Normal & 2 & 60 & $2 \mathrm{E}-05$ & 1 & $2.4 \mathrm{E}-05$ & $6.0 \mathrm{E}-10$ & $6.0 \mathrm{E}-21$ \\
\hline & & & & & & & & & & \multicolumn{2}{|l|}{ Jumlah } & $6.0 \mathrm{E}-10$ & $6.0 \mathrm{E}-21$ \\
\hline & & & & & & & & & & \multicolumn{2}{|c|}{$\begin{array}{l}\text { Ketidakpastian Baku } \\
\text { Gabungan }\end{array}$} & \multicolumn{2}{|c|}{$2.44534 \mathrm{E}-05$} \\
\hline & & & & & & & & & & \multicolumn{2}{|c|}{ Eff. DOF $\left(v_{\text {eff }}\right)$} & \multicolumn{2}{|c|}{60.000} \\
\hline & & & & & & & & & & \multicolumn{2}{|c|}{ Faktor Cakupan } & \multicolumn{2}{|c|}{2.00} \\
\hline & & & & & & & & & & \multicolumn{2}{|c|}{$\begin{array}{l}\text { Keidakpastian } \\
\text { Bentangan }\end{array}$} & 4.9E-05 & $m \cdot s^{-2}$ \\
\hline
\end{tabular}

- Perubahan ketinggian permukaan cairan

Ketidakpastian bentangan perubahan tinggi permukaan cairan dapat dilihat Tabel 4, yaitu sebesar $7.8 \times 10-5 \mathrm{~m}$, atau setara dengan $0.078 \mathrm{~mm}$. Hal ini cukup signifikan mengingat setiap perbedaan ketinggian $1 \mathrm{~mm}$ dari kedua permukaan cairan pada tabung 1 pipa-U dan tabung 2 pipa-U akan menghasilkan tekanan mendekati $10 \mathrm{~Pa}$. Nilai ini kemudian akan dimasukkan sebagai komponen utama pada penentuan ketidakpastian sistem yang dibangun, ditunjukkan pada tabel 5 .

TABLE 4. Ketidakpastian sistem pengukuran perubahan tinggi permukaan cairan.

\begin{tabular}{|c|c|c|c|c|c|c|c|c|c|c|c|c|c|}
\hline \multirow[t]{2}{*}{ No. } & $\begin{array}{c}\text { Komponen } \\
\text { Keidakpastian } \\
\end{array}$ & Esimasi & \multirow[t]{2}{*}{ Sawan } & \multirow[t]{2}{*}{ Simbol } & Lebar Distribusi & \multirow[t]{2}{*}{ Distribusi } & \multirow[t]{2}{*}{ Pembagi } & DOF & \begin{tabular}{|c|}
$\begin{array}{c}\text { Ketdakpastan } \\
\text { Baku }\end{array}$ \\
\end{tabular} & $\begin{array}{l}\text { Koofisien } \\
\text { Sensifitas } \\
\end{array}$ & \multirow[t]{2}{*}{$G_{1} u_{i}$} & \multirow[t]{2}{*}{$\left(c_{i}, u_{i}\right)^{2}$} & \multirow[t]{2}{*}{$\left(c_{1}, u_{i}\right)^{4} / v$} \\
\hline & $x$ & $x i$ & & & $2 a$ & & & vi & ui & di & & & \\
\hline 1 & Sertifikat LDS & 0 & $\mathrm{~m}$ & LC & 0.000007 & Normal & 2 & 60 & 0.0000035 & 1 & 0.0000035 & $1.2 \mathrm{E}-11$ & $2.5 \mathrm{E}-24$ \\
\hline 2 & \begin{tabular}{|c|} 
stabilitas \\
pembacaan \\
LDS
\end{tabular} & 0 & $\mathrm{~m}$ & os & 0.00004 & Segiempat & 1.73 & 50 & 1.1547E-05 & 1 & $1.155 \mathrm{E}-05$ & $1.3 \mathrm{E}-10$ & $3.6 \mathrm{E}-22$ \\
\hline 3 & Kemiringan & 0 & $\mathrm{~m}$ & $L \theta$ & 0.000125 & Segiempat & 1.73 & 50 & $3.6084 \mathrm{E}-05$ & 1 & $3.608 \mathrm{E}-05$ & $1.3 \mathrm{E}-09$ & $3.4 \mathrm{E}-20$ \\
\hline \multirow[t]{6}{*}{4} & Histeresis & 0 & $\mathrm{~m}$ & Lh & 0.00003 & Segiempat & 1.73 & 50 & 8.6603E-06 & 1 & $8.66 \mathrm{E}-06$ & $7.5 E-11$ & $1.1 \mathrm{E}-22$ \\
\hline & & & & & & & & & & \multicolumn{2}{|l|}{ Jumlah } & $1.5 \mathrm{E}-09$ & $3.4 \mathrm{E}-20$ \\
\hline & & & & & & & & & & \multicolumn{2}{|c|}{ Ketidakpastian Baku } & \multicolumn{2}{|c|}{$3.90214 \mathrm{E}-05$} \\
\hline & & & & & & & & & & \multicolumn{2}{|c|}{ Eff. DOF $\left(v_{\text {off }}\right)$} & \multicolumn{2}{|c|}{67.440} \\
\hline & & & & & & & & & & \multicolumn{2}{|c|}{ Faktor Cakupan } & \multicolumn{2}{|c|}{2.00} \\
\hline & & & & & & & & & & \multicolumn{2}{|c|}{$\begin{array}{l}\text { Keidakpastian } \\
\text { Bentangan }\end{array}$} & $7.8 \mathrm{E}-05$ & $\mathrm{~m}$ \\
\hline
\end{tabular}

TABLE 5. Ketidakpastian sistem kalibrasi tekanan rendah.

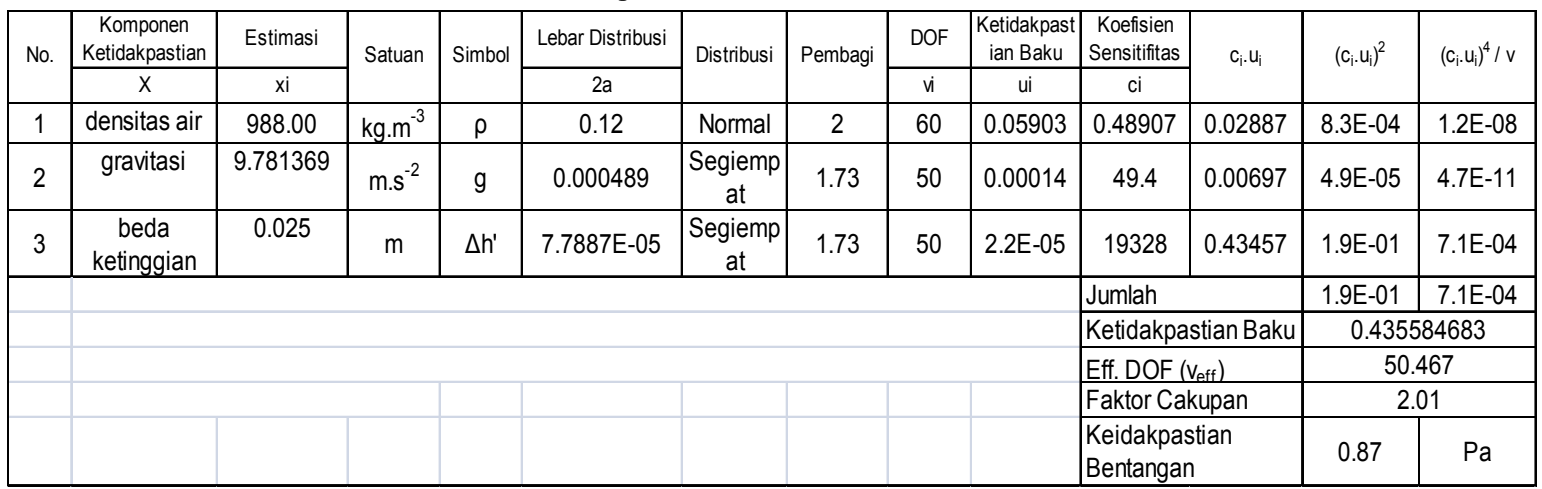

Ketidakpastian sistem kalibrasi primer yang sedang dibangun ditampilkan pada tabel 5, berupa ketidakpastian bentangan dengan faktor cakupan $\mathrm{k}=2$ dengan tingkat kepercayaan $95 \%$. Besarnya ketidakpastian bentangan yang diperoleh adalah $0.87 \mathrm{~Pa}$ atau setara dengan $0.18 \%$ 
dari skala maksimum (full scale-FS). Nilai ini cukup untuk melakukan kalibrasi bagi alat ukur tekanan yang memiliki rentang tekanan rendah dengan akurasi sampai dengan $0.8 \%$.

\section{Validasi Sistem Dengan Standar Primer Yang Lain}

Validasi sistem kalibrasi alat ukur tekanan rendah yang dibangun bertujuan yang pertama adalah untuk mengetahui seberapa jauh kesalahan atau penyimpangan pengukuran sistem yang dibangun, serta untuk mengetahui seberapa jauh kemampuan sistem untuk dapat digunakan sebagai standard, yang kedua bertujuan untuk melakukan upaya ketertelusuran standard primer ke standard yang lebih tinggi sesuai dengan hirarki rantai ketertelusuran standard ukur tekanan.

Dengan tujuan tersebut maka penulis melakukan kerjasama dengan lembaga berwenang yaitu Puslit Metrologi LIPI sebagai lembaga tertinggi nasional bidang metrologi atau National Metrology Institute (NMI) di Indonesia, untuk melakukan validasi sistem kalibrasi alat ukur tekanan rendah yang dibangun. Hasil validasi yang dilakukan Puslit Metrologi Lipi disampaikan pada tabel 6.

TABEL 6. Hasil yang diperoleh dari validasi sistem kalibrasi alat ukur tekanan rendah dengan standard primer lain.

\begin{tabular}{|c|c|c|c|c|c|c|c|}
\hline \multirow{2}{*}{ No } & $\begin{array}{c}\text { Massa } \\
\text { Tambahan }\end{array}$ & $\Delta \mathrm{P}_{\text {STD }}$ & $\Delta \mathrm{h}$, & $\mathrm{T}$ & $\Delta \mathrm{P}_{\text {SYSTEM }}$ & $\begin{array}{c}\text { Kesalahan } \\
\left(\Delta \mathrm{P}_{\text {SYSTEM }}\right. \\
-\Delta \mathrm{P}_{\text {STD }}\end{array}$ & $\begin{array}{c}\text { Kesalahan } \\
\text { Relatif } \\
\mathrm{FS}\end{array}$ \\
\cline { 2 - 8 } & $(\mathrm{g})$ & $(\mathrm{Pa})$ & $(\mathrm{mm})$ & $\left({ }^{\circ} \mathrm{C}\right)$ & $(\mathrm{Pa})$ & $(\mathrm{Pa})$ & $(\%)$ \\
\hline 1 & 0 & 0 & 0.01 & 17.46 & 0 & 0 & - \\
\hline 2 & 10 & 101.13 & 5.22 & 17.47 & 101.98 & 0.9 & $0.17 \%$ \\
\hline 3 & 20 & 200.99 & 10.33 & 17.55 & 201.82 & 0.8 & $0.16 \%$ \\
\hline 4 & 30 & 300.85 & 15.38 & 17.95 & 300.46 & -0.4 & $0.08 \%$ \\
\hline 5 & 40 & 400.71 & 20.49 & 17.96 & 400.28 & -0.4 & $0.09 \%$ \\
\hline 6 & 50 & 500.57 & 25.66 & 17.97 & 501.18 & 0.6 & $0.12 \%$ \\
\hline
\end{tabular}

Hasil validasi sistem kalibrasi alat ukur tekanan rendah yang dibangun sesuai dengan tabel 6 ini bisa dikatakan memuaskan, karena kesalahan relative dari sistem yang dibangun berada didalam rentang ketidakpastian yang diklaim pada tabel 6 yaitu $0.18 \%$.

\section{KESIMPULAN}

Berdasarkan pengujian yang telah dilakukan terhadap sistem kalibrasi alat ukur rendah yang dibuat, diperoleh hasil bahwa sistem kalibrasi alat ukur tekanan rendah yang dibuat memiliki rentang ukur 10 pascal sampai dengan 500 Pascal.

Besarnya ketidakpastian bentangan dari Sistem Kalibrasi Alat Ukur Tekanan Rendah rentang ukur tekanan 10-500 pascal yang dibangun diperoleh $0.87 \mathrm{~Pa}$ atau setara dengan $0.18 \%$ dari skala maksimum (full scale-FS). Pada tingkat kepercayaan 95\% dan faktor cakupan $\mathrm{k}=2$.

Sistem Kalibrasi Alat Ukur Tekanan Rendah yang dibangun, terbukti dapat digunakan sebagai standard primer untuk melakukan kalibrasi bagi alat ukur tekanan yang memiliki rentang tekanan rendah dengan akurasi sampai $0.8 \%$.

Dengan melakukan uji validasi antara Sistem Kalibrasi Alat Ukur Tekanan Rendah yang dibangun dengan sistem standard primer yang lain oleh Puslit Metrologi LIPI dikatakan memuaskan karena kesalahan relative dari sistem yang dibangun berada didalam rentang ketidakpastian $0.18 \%$. 


\section{DAFTAR PUSTAKA}

[1] M. Tanaka, G. Girard, R. Davis, A. Peuto, and N. Bignell, "Recommended table for the density of water between $0 \mathrm{C}$ and $40 \mathrm{C}$ based on recent experimental reports 1," vol. 301, 2001.

[2] L. Cuscó and E. Sparks, Guide to the Measurement of Pressure and Vacum. London: Institute of Measurement and Control, 1998.

[3] F. Pavese and G. Molinar Min Beciet, Modern Gas-Based Temperature and Pressure Measurements. 2013.

[4] J. C. F. G. I. M. Jcgm, "JCGM 200 : 2008 International vocabulary of metrology — Basic and general concepts and associated terms ( VIM ) Vocabulaire international de métrologie - Concepts fondamentaux et généraux et termes associés ( VIM )," Int. Organ. Stand. Geneva ISBN, vol. 3, no. Vim, p. 104, 2008.

[5] Komite Akreditasi Nasional "ISO/IEC 17025 (Versi Bahasa Indonesia)-Persyaratan Umum Kompetensi Laboratuirum Pengujian dan Laboraturium Klibrasi. 2005

[6] Guideline DKD-R 6-1, " Calibration of Pressure Gauges". Physikalisch-Technische Bundesanstalt. 2003

[7] BS-EN837-1 Standard, Pressure gauges. European Committee for Standardization, 1998.

[8] International vocabulary of metrology (VIM), "Basic and general concepts and associated terms". JCGM 200:2008.

[9] Working Group 1 of the Joint Committee for Guides in Metrology (JCGM/WG 1), "Guide to the expression of uncertainty in measurement ".1993. 